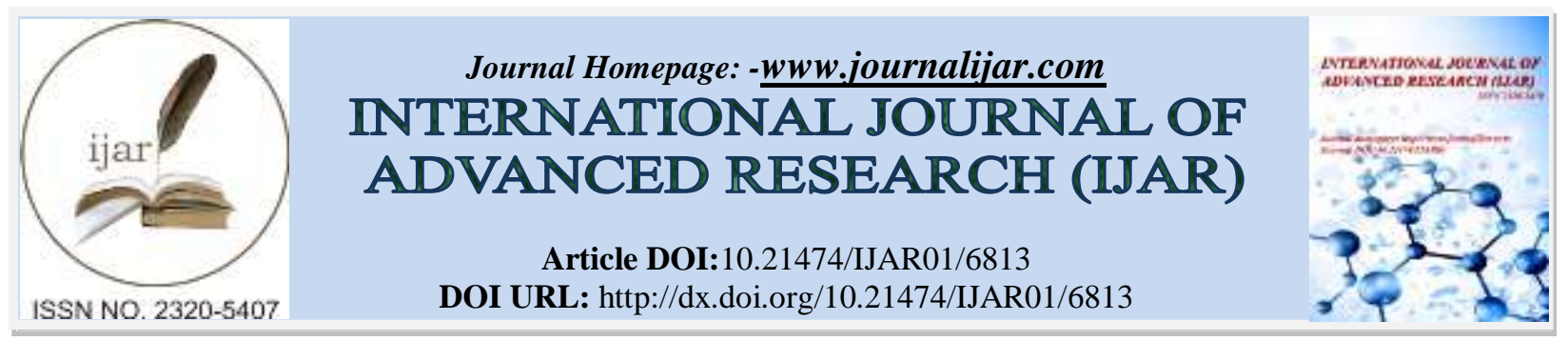

RESEARCH ARTICLE

\title{
REAL TIME CHILD MONITORING SYSTEM BASED ON RASPBERRY PI AND BEACON TECHNOLOGY USING ANDROID APP.
}

\author{
Rameesa. $\mathrm{O}^{1}$, Prof. C Periasamy ${ }^{2}$ and Ms. Priyanka. M. $\mathrm{T}^{3}$. \\ 1. Rameesa.o student VVIT. \\ 2. Prof. C Periasamy Head of ECE department. \\ 3. Ms.Priyanka.M.T Asst. Professor.
}

Manuscript Info
Manuscript History
Received: 22 January 2018
Final Accepted: 24 February 2018
Published: March 2018
Keywords:-
Raspberry Pi, Website, Pi Camera,
Raspbian OS, PHP, iBeacon, Android
App.

\begin{abstract}
This paper proposes a secure child monitoring system that can be accessed online through the website with authorized parties. It uses Raspberry Pi microcomputer and a Pi camera in order to capture real time video so as to develop a web based system where Python and PHP software are used. This system provides security and safety in monitoring their children remotely. A Bluetooth based iBeacon technology with Android app is developed to detect the current floor position of the children in the daycare. iBeacon technology is based on the Bluetooth Low Energy (BLE) and Received Signal Strength (RSS) . Smartphone Application for interacting with the beacons is developed for Android device. It allows the user to determine the distance between the child and individual beacon.
\end{abstract}

Copy Right, IJAR, 2018,. All rights reserved.

\section{Introduction:-}

The system is designed for assisting parents in monitoring their children who work away from the childcare, nowadays most of the parents are working and they cannot be with their child all the time, hence majority of parents kept their children in daycare. Daycare or childcare is a place with more population of children. In order to ensure the security of child in childcare security cameras were installed in childcare. Parents need to monitor their children because children nowadays are having many threats. In this proposed system we are building a child monitoring system that can be accessed online through website with authentication feature and using Bluetooth iBeacon technology with android app is used to track the current floor position of children in daycare.

This paper deals with the design and development of a web-based child monitoring system with real time features. iBeacon works on received signal strength based localization method. Smart phone application allows the user to calculate the distance from any individual beacon.

The purpose of this work is to build a real time child monitoring system based on raspberry pi microcomputer and iBeacon technology using Android App, the system can be accessed online through the website by authorized parties using login id and password. The system is build to assist parents in taking care of their child remotely and reduce child abuse in wide extent. iBeacons are low powered, low cost radio transmitters that notifies nearby devices of their presence and can be used by android OS. 


\section{Related Work:-}

OkkyPermatasari, SitiUmmiMasruroh and Arini MT introduced a prototype of child monitoring system using motion and authentication with Raspberry Pi [1].This project usesRaspberry Pi with web camera in order to monitor the children with real time video. A web camera is connected to the raspberry pi to capture video and images. This monitoring system helps parents in monitoring their child remotely and provide security and safety against child abuse. The major advantage of this project includes real time monitoring and online access of the video. In conclusion this system is a very useful tool for child monitoring and this will protect child and avoid unnecessary worries about child.

M.Naveenkrishna, Dr.S.Jayanthy 2 introduced Beagle Bone Black webcam server for security [2]. This project is based on ARM-Cortex-A8 processor and Linux operating system, It consist of Beagle bone black ( low cost expandable computer launched by Texas instrument ) with Linux operating system(Angstrom) interfaced with webcam. serves the files that form Web pages to Web users. A web server can be deployed in to a device which can be accessed remotely from a web server; this embedded system can serve the web documents on request by a client from other system. The client can access the web server by proper authentication. This displays the webpage forms like home, video, upload, setting and about. The server consists of a power supply board, Beagle Bone Black, webcam and HDMI monitor. In this project the video streaming media using Beagle Bone Black computer is implemented and video is saved in the server and the client can access or download the video using client with proper authentication and id, and this system provides a way to upload videos by client.

\section{Proposed System:-}

An admin of a childcare has the authorization to maintain the childcare by keep track the list of all children, status etc.., and their history to give a pleasant environment. In this proposed system the childcare admin facilitate a way to monitor child remotely by online through real time video surveillance, this system can be accessed online through the website with authentication feature.

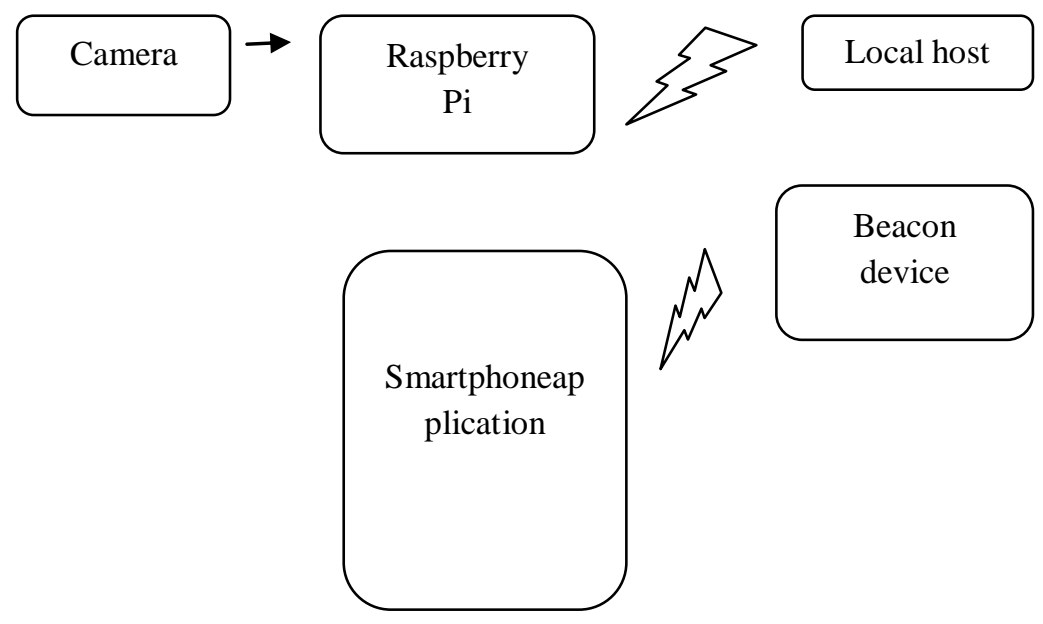

Fig. 1:-Block diagram proposed system

The system architecture consist of following blocks, the first part of this project is raspberry pi and camera which is the heart of the project. Any version of raspberry pi will work excepting Pi3 model with provision of Wi-Fi. The Pi camera, a small circuit board is connecting to Raspberry Pi bus connector. The second part contains an iBeacon device with android app to detect the current floor position of the children in the childcare. The Beacon device works on received signal strength based localization method and with Smartphone application by which the user can determine the exact distance from individual beacon.

\section{Hardware Needed:-}

1. Raspberry pi 3 model B

2. Pi camera

3. 5v 2A power source

4. LAN cable 
5. iBeacon technology

6. Smartphone application

Each of the blocks will be explained detail in the following section.

\section{Raspberry Pi:-}

The Raspberry Pi3 model B is the latest version of Raspberry Pi with advanced features including Broadcom BCM 2837b 64bit Quad Core CPU at 1.2 Ghz,1GB RAM and onboard Bluetooth 4.1 Wi-Fi, full size HDMI video output. Any version of Raspberry pi will work with exemption of pi 3 models which has the provisions for Wi-Fi.

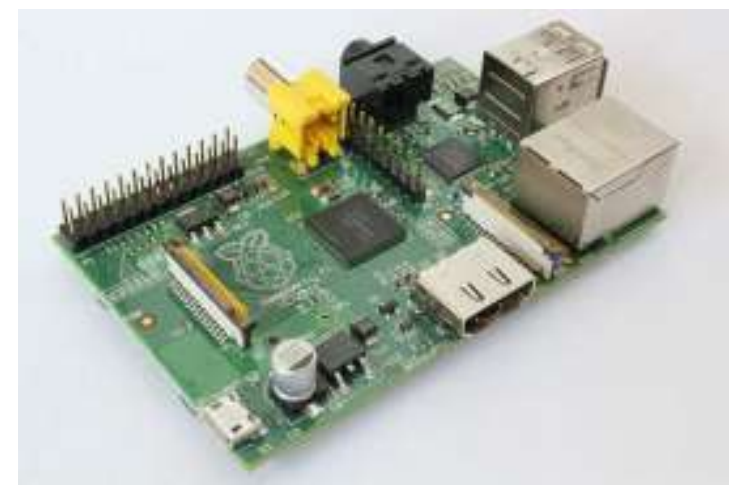

Fig. 2:-Block diagram of Raspberry pi

\section{Camera:-}

The pi camera consisting of a small circuit board which links the Raspberry Pi's camera serial bus interface (CSI) connector through flexible ribbon cable. The camera has a native resolution of 5 mega pixel and has fixed focus lens and here the software for camera supports full resolution. The camera supports video resolution of 1080p 30, 720p 60 and $640 * 480$ p 60/90.

1. The camera module consists of a small camera board and cable.

2. Connect ribbon cable to the CSI connector on the Raspberry pi board

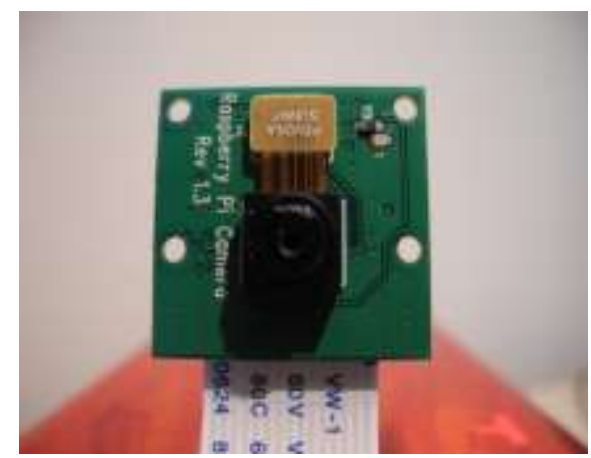

Fig. 3:-Pi camera

\section{IBeacon Technology:-}

iBeacon technology is based on the Bluetooth low energy and it works by received signal strength based localization method to determine the current floor position of the user. IBeacons are used by apps to trigger events and allows users to interact with digital or physical things. 


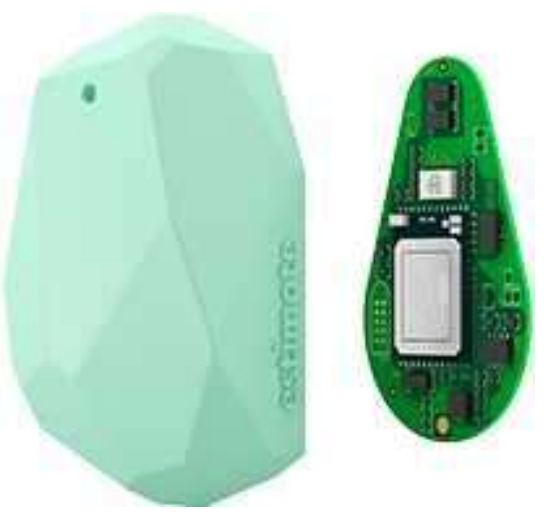

Fig. 4:-iBeacon device

The standard beacon consists of an UUID, a Major and a Minor value,

1. UUID: unique ID to distinguish the iBeacon from one another.

2. Major id: used to specify a specific iBeacon in a group.

3. Minor id: used to group related sets of iBeacon.

\section{Smartphone Application:-}

The application is developed for interacting Beacon devices with android mobile phones. This mobile OS allows users to develop and can be downloaded onto other phones without the need of an official app store, which allows users to check out distance from any individual beacon.

This android app is intended for determining the current location of the user by using location algorithm, which will then send location, user id to the server, this process will be repeatedly done for a certain time interval to keep the track of child in the daycare or this can be developed at home. This application is developed for android smart phones using android studio.

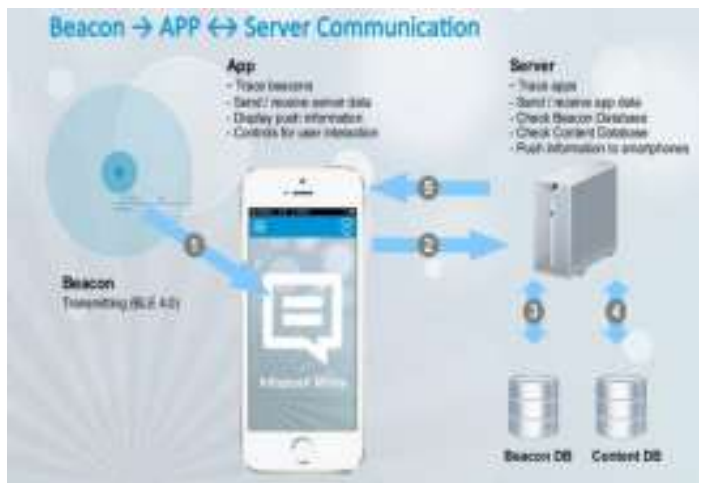

Fig. 5:-IBeacon App server communication

\section{Working:-}

Desktop of Raspbian shall be opened and connect to Wi-Fi by putting the correct password. When the Raspbian is connected to the network by Wi-Fi, then shut down the system.

1. Open your browser on laptop or mobile. (laptop or mobile has to be in the same network as the pi )

2. Go to your Router settings by typing in the default IP address of your router. (Written somewhere on your router)

3. Find the list of connected devices.

4. Find the corresponding IP address of the device named raspberry.

While doing above operations the following points may be kept in mind:

1. IP address is 192.168.0.107

2. Open up Putty and type in the IP address of your Pi and connect. 
3. 'pi' \& 'raspberry' is the default 'login as' and 'password' in Raspbian.

4. It is always a good practice to Update and Upgrade the system as soon as you log in.

5. To do it, type in the command 'sudo apt-get update' and 'sudo apt-get upgrade' one at a time.

6. First of all one have to restart the motion software. To do it type in the command 'sudo service motion restart' and press enter.

7. Again type in the command 'sudo motion' and press enter. Now server is ready.

\section{Use Case Diagram:-}

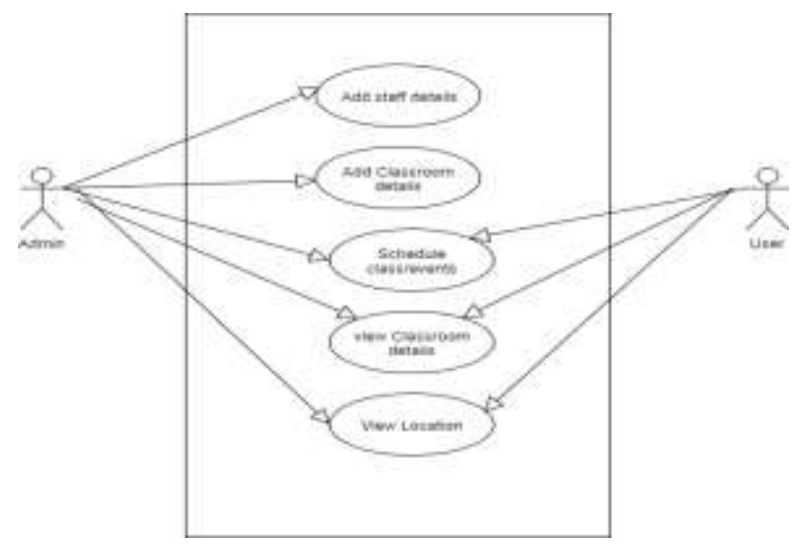

Fig. 6:- Case diagram

\section{Admin module:-}

The main task of admin module is to add and update staff details and time table. The time table contains details of various events and classes arranged in a particular department.

\section{User module:-}

After registration and login process user module can view the various events updated by admin based on his current location. Also user will get a graphical representation of his location in smart phone.

\section{Results:-}

Thus we successfully developed real time child monitoring system based on Raspberry pi and iBeacon using android App to help parents in monitoring their child remotely. This is a very useful system to track the location of the child using iBeacon and android app. The experimental results shows the system works successfully and results of the proposed system is shown below.

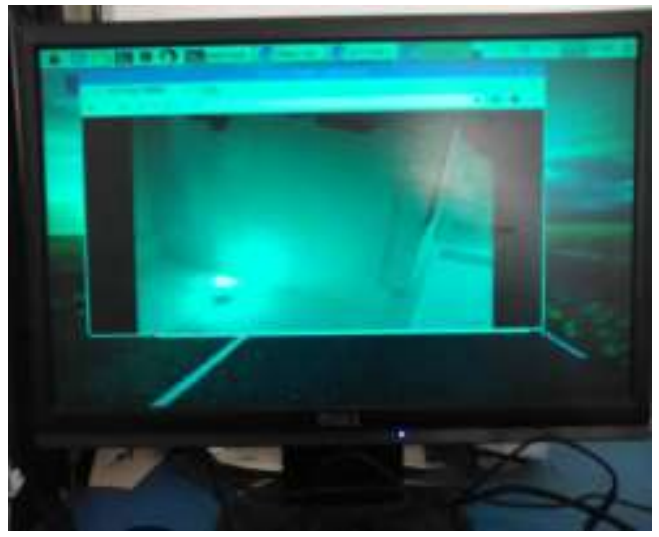




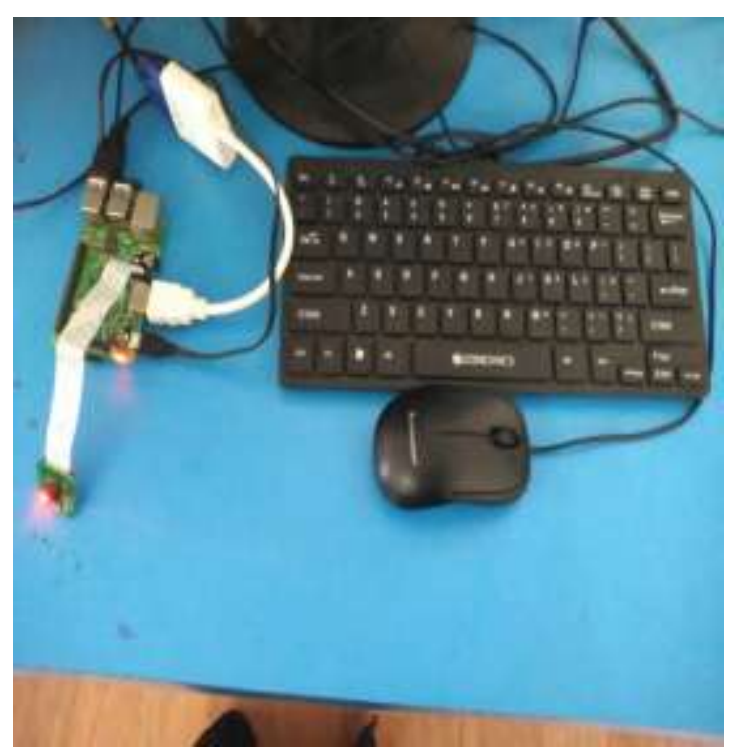

Fig. 7:- Proposed system setup

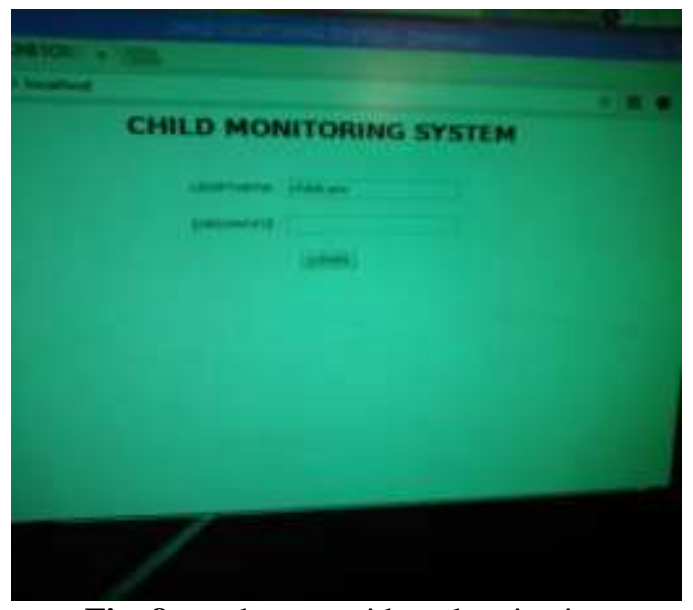

Fig. 8:- web page with authentication

Fig. 9:- Online monitoring

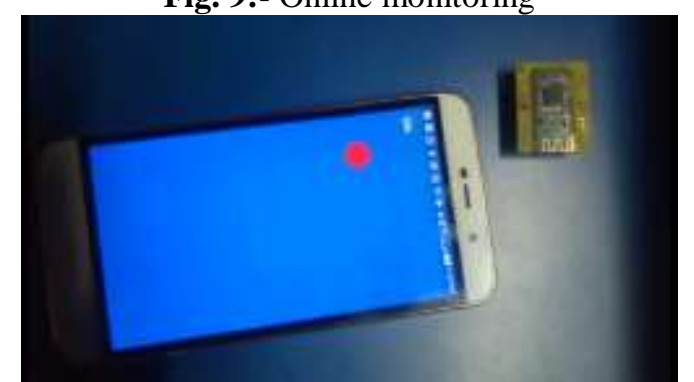

Fig. 10:-iBeacon technology with Android app

\section{Conclusions:-}

Thus this project developed a real time Child Monitoring System with Raspberry Pi and iBeacon device to monitor child and can be accessed online through website. Definitely this system will help parents in monitoring their child remotely and provide children safety against child abuse occurs around world widely. This design is secured from unauthorized parties by proper login id and password. An important feature of this project is the current floor location of the child using iBeacon. 


\section{References:-}

1. Chirag Yadav Department of Computer Engineering MITCOE, Pune AnkitPandey Department of Computer Engineering MITCOE, Pune MayankSaraogi Department of Computer Engineering MITCOE, Pune ShubhamTribhuwan "Active RFID and ESP8266 based Child Monitoring System"International Journal of Computer Applications (0975 - 8887) Volume 139 - No.12, April 2016

2. Gopinath.s,T.Devika,L.Manivannan,Dr.N.SuthanthiraVanitha "Rescue Child from Bore well using Embedded System" International Research Journal of Engineering and Technology (IRJET) e-ISSN: 2395 -0056 Volume: 02 Issue: 03 | June-2015 www.irjet.net p-ISSN: 2395-0072

3. J. Li, "Characterization of WLAN Location Fingerprinting Systems", Institute of Computing Systems Architecture School of Informatics, University of Edinburgh, 2012.

4. Miss.TruptiR.Chaudhari, Dr.A.J.Patil, Mr.R.R.Karhe "RFID and GPS based child tracking system with voice recognition for security" ISSN: 2455-2631 @ December 2016 IJSDR | Volume 1, Issue 12

5. Naveenkrishna,M Dr.S.Jayanthy2 introduced Beaglebone Black Webcam Server For Security.

6. OkkyPermatasari, SitiUmmiMasruroh M.Sc., Arini, MT introduced A Prototype of Child Monitoring System Using Motion and Authentication with Raspberry Pi

7. Prof. PramodGanjewar, ShaileshBandle, Prasad Waghmare introduced Wireless Automated Video Surveillance System Using Motion Detection Method.

8. Prof. Sundar S RohanGhosh and Harris Shahil proposedA Prototype of Automated child Monitoring System.s

9. S. Sand, A. Dammann and C. Mensing, "Positioning in Wireless Communications System", German Aerospace Center (DLR), Germany, ISBN: 978-0-4707-7064-1, Feb 2014.

10. Shatha K. Jawad, Al-Gawagzeh Mohammed Yousef, Balkiest Essa Al-Shagoor introduced A Multipurpose Child Tracking System Design and Implementation system.

11. Yanfei Liu proposed A Robotic Prototype System for Child Monitoring. 